\title{
ANALYSE AND GRAPHICAL REPRESENTATION ON IMPLEMENTATION OF NEW ISO/DIS 14001:2015 REVISION IN AUTOMOTIVE INDUSTRY
}

\author{
Alina Mihaela FAGATEANU \\ Continental Automotive Systems S.R.L., Sibiu (Romania) \\ alina.fagateanu@gmail.com \\ Sergiu Ștefan NICOLAESCU \\ Continental Automotive Systems S.R.L., Sibiu (Romania) \\ sergiu.nicolaescu@ulbsibiu.ro \\ Claudiu Vasile KIFOR, \\ Lucian Blaga University of Sibiu, Sibiu (Romania) \\ claudiu.kifor@ulbsibiu.ro
}

\begin{abstract}
We live in a dynamic world that is constantly changing in order to lighten our daily activities. All changes made must meet several conditions, most of them having a direct relationship with the environment and are applicable for more than one person. Considering that in this moment the standard for environment protection has passed the review period and will be published in the near future, the present article aims to highlight the most important changes from the new version of ISO / DIS 14001: 2015.The information is structured for the organizations which holds the old version ISO 14001: 2004, so, the necessary steps to follow can be easily understood while moving totally to the new version.
\end{abstract}

Keywords: environmental management system, ISO 14001, management, improvement.

\section{Introduction}

ISO 14001 is an International Standard, accepted all across the world that sustain that better enviromental performance can be achieved when enviromental aspects are identified and managed[1]. The purpose is to live in a greener, safer world that offer quality for people on short term through products and, also on long term, throught enviromental performance[2]. All full ISO standards require to be reviewed every 5 years (ISO Directive Part 1, Cl. 2.9.1); the review can confirm that there is no change, but normally improvements are needed [3], therefore new integrations will be done inside organizations.

In figure 1 is captured the evolution of the ISO14001 implementation inside organizations from Roumania until year 2013 when it reached the number

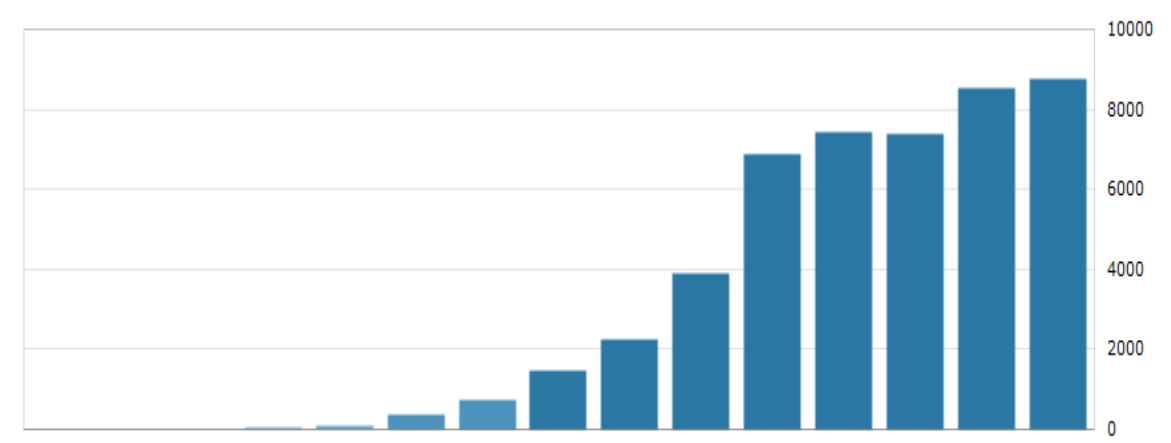

199920002001200220032004200520062007200820092010201120122013 
of 8744 certified companies [7].

For an overview regarding the evolution in the whole world, below is presented the evolution of certification structured in: Africa, Central / South America, North America, Europe, East Asia and Pacific, Central \& South Asia and Middle East.

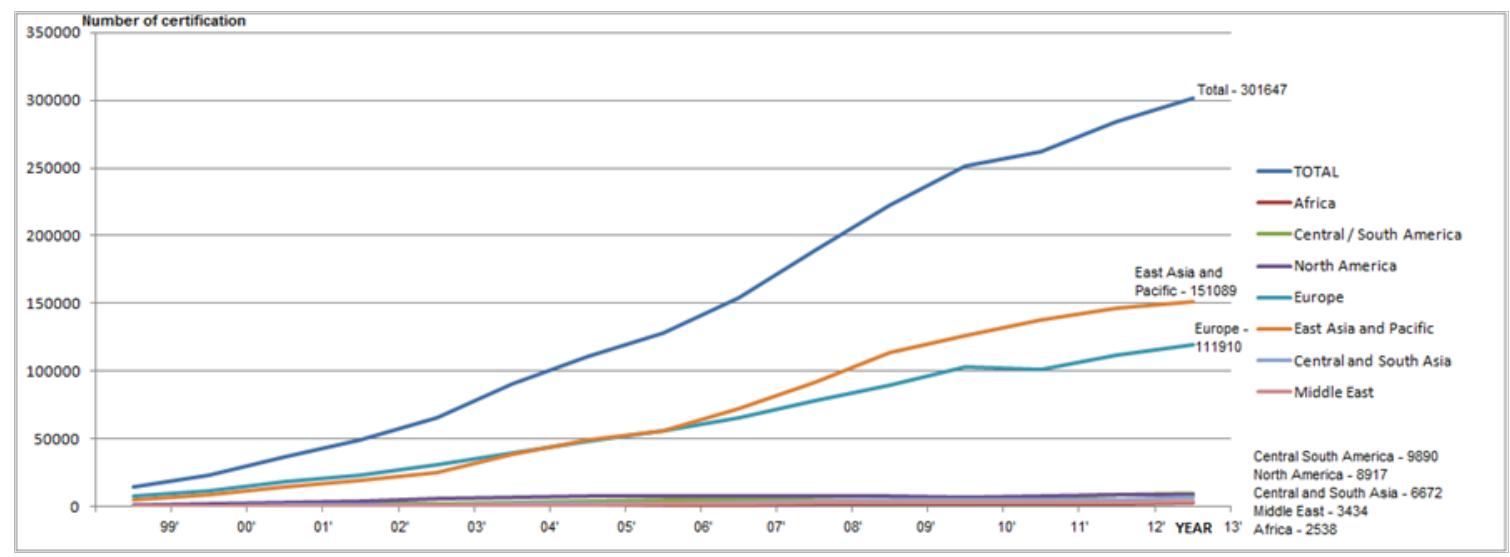

Figure 2. Evolution of ISO14001 certification world-wide [7]

It can be observed that ISO 14001 standard is spread all acros the world and it's important to for the companies to undestand what are the changes in the revision from 2015.

Many companies include the elements of performance management into their Environmental Management System based on the ISO 14001, while others fail because there is no explicitly requested into certification.[4] The principal objective of implementing an Environmental Management System is to improve continuously organization's environmental performance.

Benefits of successful implementation of an Environmental Management System would include cost reduction of pollution prevention activities, compliance with legislation requirements and a better organizational image on internationally and locally.[5]

This paper starts with the background of the environmental standard and will be continued with an analyse of the changes that will offer a startup for companies that wants to migrate to ISO 14001:2015 in the near future. The automotive sector is lately into a continuous concern regarding enviromental and innovation[13], so we decided to focus on this area. During research were used bibliographic research, observational study and interviews inside a big organisation from automotive industry.

\section{Backround}

ISO 14001 was first published in 1996, but until then in some countries certain national environmental standards already existed. An example were the British that created the first environmental protection standard, BS7750, in 1994 [5]. In the same year, Canada created the Z750 standard[10]. In United States there was no national standard developed in the 1990s, but in 1994 appeared the GEMI Institution (Global Environmental Management Initiative). Certainly, the first international environmental management system ISO 14001 was developed by ISO.

The main characteristics that made the foundation of standard are the followings:

$\rightarrow$ International interest was increased: In year 1992 taked place the first Earth Summit in Rio where was signed a global commitment to the environment. In the same year, BSI Group

(British Standards Institute) published the first standard for environmental management systems. This being the basis for developing the ISO 14000 series in 1996 by the International Organization for Standardization (ISO).

$\rightarrow$ The success of ISO 9001: the standard has many features in common with its predecessor ISO 9000, International Quality Management Standard, which served as a model for its internal structure. Like ISO 9000, ISO 14000 acts as an internal management tool and as a way to demonstrate environmental commitment of a company to its customers. 
Since 1996, ISO 14001 Environmental Management System imposed a new perception becoming a concept "in vogue" and applicable to any type of organization; now it's the most popular system of environmental management being implemented in 300,000 organizations spread on over 160 countries [7].

In 2004 the standard was republished with minor changes on language requirements and key terms of ISO 9001. After four years, in 2008, ISO 14001 was revised and ISO 14001: 2015 is the first full version of the publication that comes when industrial and social environment is facing new challenges and changes of attitude.

At the end of 2011 was voted the revision of ISO 14001 by representatives of standardization chambers and during early 2012 the process of revision began. In July 2014 appeared the first draft "ISO / DIS 14001: 2015" and on August 28, for 3 months, was available for review and vote by authorized representatives of the National Council of Standards, which is the fourth stage of the third phases of the review process.

The review of International standard can be summarized like process flow from figure 3.

After the review process is completed, changes can be proposed in a final project ISO/FDIS 14001:2015 that will be published in may 2015, final version being published in october

2015. All ISO standards are revised every five years to meet the continuing changing needs of enterprises that have it implemented.

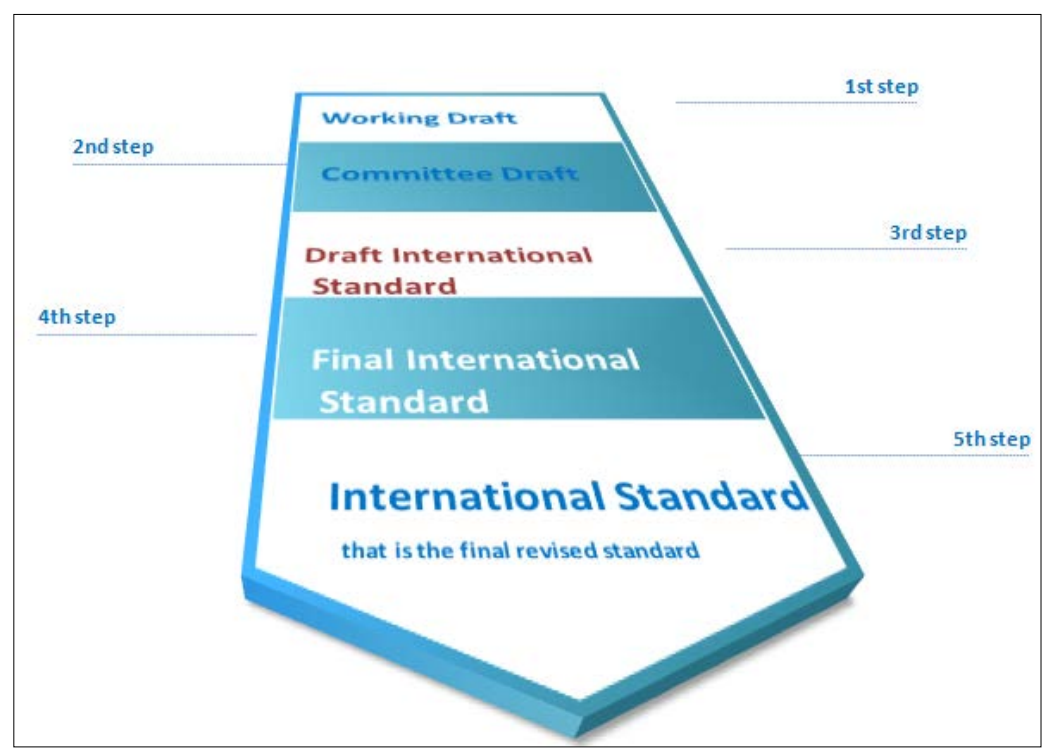

Figure 3. ISO Review phases

The draft ISO / DIS 14001: 2014 is already available and includes many major changes in the structure, being adopted the structure of Annex SL. After July 2015, the companies that are certified to ISO 14001: 2004 or corrected version 2008, will have 3 years (until July, 2018) for the transition on the new ISO 14001: 2015, after this the old certification will be invalid.[12]

Companies that wish to implement ISO 14001: 2015 will be able to do it only after 18 months from the publication of final version in July 2015.

\section{ISO14001:2015 structure}

Integration of common platform that includes Annex SL structure and a review of the environmental management system, will ensure the consistency and the easily integration of several standards in the same organization. In figure 4 are represented the changes of ISO 14001 from new standard revision. They are represented according to the model of Deming PDCA which lies at the heart of ISO 9000 and is a cyclical pattern and systematically based on a preventive approach and continuous improvement in the automotive industry.

Graphical representation is respecting the system environmental management cycle of implementation and maintenance inside organization, in accordance with the diagram of the old revision of standard. The figure includes all the requirements of the new revision, the number and the text of ISO / DIS: 2014, highlighting via different colors, the new and the unchanged requirements. 


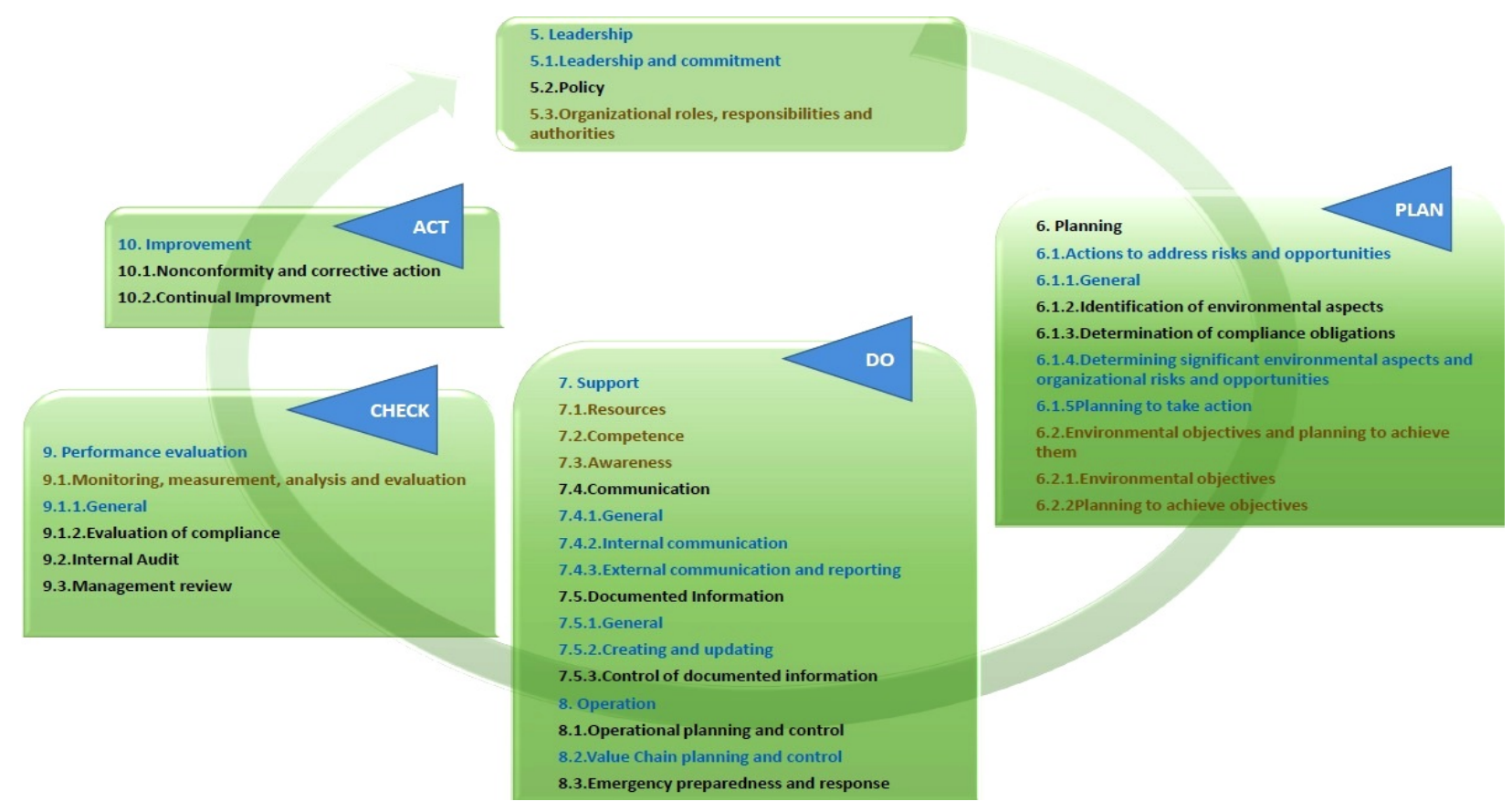

Figure 4. ISO 14001 graphical changes (adapted from [8])

Another change in new revision is the highlighting of technological advances for managing information (e.g. digital with computers, tablets and even cloud based systems) from now will use the term 'documented information', instead of 'documents' and 'records[3]. Because the enviroment is in continous change, the development of organisations depends greatly on the exploition of knowledge inside it [9], to learn from previous mistakes and gather all this asset of the organisation.

First of all, this standard requires from companies to set their environmental policy and objectives themselves. The identification of environmental aspects and compliance with the law are usually stated as important and requiring most effort.[3]

\section{Review on new revision}

The first and most important aspect included in the revision of ISO / DIS 14001: 2015 is Annex SL. This structure makes the standard more consistent and much easier to integrate with all ISO Management Systems, because it has 10 clauses, common terminology and definitions.

The second aspect is a lifecycle approach that increases the organizations focus on the impact that their products / services have on the environment, from raw material sourcing to product recycling.[11]

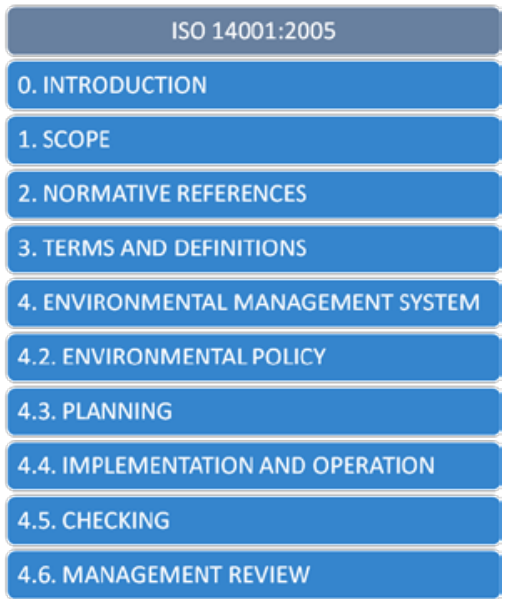

Figure 5. Differences of the ISO 14001 structure[14]

Other aspect is the control of outsourcing, the focus is to keep control or influence the activities to be outsourced in accordance with the requirements of the Environmental Management System.

The fourth issue is context as an organization focused on protecting the environment, including reliability for organizations to demonstrate their understanding of all environmental impacts. 
Other new requirements that makes a difference into the new revision are the information documentation and a high attention regarding risks.

The standard users need to understand the right meaning of the term "risk". First of all, the assessment of significant aspects will need to be integrated in the strategic risk management. [6] To make advantage of this step is needed to identify and assess the risks that develops into negative environmental aspects or risks that can have positive impact on environmental aspects. These identified risks can also be associated with legal and other requirements. After risks are identified and anlysed, it is proposed that all risks from all these various sources will be integrated into an action plan.[14]

\section{Conclusions and further applicable work}

Implementation of this change will be beneficial for organization throught improvement of performance and reduction of documentation regarding the environmental management system.

It has been chosen to adopt a graphical representation of the new ISO 14001 revision and its requirements. It is generally know that a picture worths 1000 words and it is much easier to be understood. The graphical representation is a statistical technique, because it synthesises absolute data which can show evolutionary trends.

Documentation for environmental management system will be more flexible for the new revision because it will include only mandatory requirements. Having a common structure with ISO 9001 it will be much easier to understand and implement.

It can be observed that the documentation and knowledge management is needed inside the organizations for keeping their product competitive; therefore in the following work we intend to analyse the integration of knowledge management concepts into the ISO14001 standard.

\section{References}

1. Da Fonseca, L. M. C. M., ISO 14001: 2015: An improved tool for sustainability. Journal of Industrial Engineering and Management, 8(1), 37-50. (2015)

2. László Berényi (2015), On the Way of Sustainability: Frameworks for Organisational Development, The international Journal of Business \& Management, Vol 3, Issue 2, February, (2015).

3. Luis Miguel Ciravegna Martins da Fonseca, „ISO 14001:2015: An Improved Tool for Sustainability”, Journal of Industrial Engineering and Management JIEM, 8(1): 37-50 - Online ISSN: 2013-0953 - Print ISSN: 20138423 http://dx.doi.org/10.3926/jiem.1298 , (2015)

4. SNEŽANA ŽIVKOVIĆ, LJILJANA TAKIĆ, NENAD ŽIVKOVIĆ, The Improvement Of Environmental Performances By Applying Iso 14001 Standard - A Case Study, Chemical Industry \& Chemical Engineering Quarterly 19 (4) 541-552 (2013)

5. Ho Lee Lee1* and Law Puong Ling, „Impact Of Implementation Of Iso 14001 Environmental Management Systems On Environmental Performance: A Case Study”, ISSN 2319-5991 www.ijerst.com, Vol. 4, No. 1, February (2015)

6. Lloyd's Register LRQA „ISO14001:2015 - What does it mean for your organisation?

7. http://www.iso.org/iso/home/standards/certification/isosurvey.htm?certificate=ISO\%209001\&countrycode=RO \#countrypick, accessed in 20.04.15

8. ISO, E. 14001: 2004. Environmental management systems-Requirements with guidance for use (ISO 14001: 2004), (2004)

9. Nicolaescu Sergiu Ştefan, and Claudiu Vasile Kifor. "Knowledge Management in Automotive Industry--Steps and Customer Focus." Quality-Access to Success 15.143 (2014).

10. Stephen J. Randall, Herman W. Konrad, „NAFTA in Transition“ ISBN1-895176-63-8, DWFriesen, Canada, 1995 p319.

11. SAI GLOBAL | Assurance Services „ISO 14001:2015 Draft International Standard

Proposed revisions to the environmental management and its progression towards final publication.“

12. CRA EUROPE, „10 key themes you need to know about the ISO 14001 Revision“ March (2014);

13. Orsato, R. J., \& Wells, P., U-turn: the rise and demise of the automobile industry. Journal of Cleaner Production, 15(11), 994-1006, (2007).

14. BSI „ISO 14001:2015 WhitepaperISO RevisionsUnderstanding the proposed changesApproaching change” available to download from http://www.bsigroup.com. 